\title{
IoT Based Smart Kitchen System
}

\author{
Shubham More ${ }^{1}$, Shridhar Shelar ${ }^{1}$, Vaibhav Randhave ${ }^{1}$, Prof. Ashwini Bagde ${ }^{2}$ \\ ${ }^{1}$ Department of Electronics and Telecommunication Engineering, D.Y.P.S.O.E, Maharashtra, India \\ ${ }^{2}$ Professor, Department of Electronics and Telecommunication Engineering, D.Y.P.S.O.E, Maharashtra, India
}

\begin{abstract}
Article Info

Volume 8, Issue 3

Page Number: 479-485

Publication Issue :

May-June-2021

\section{Article History}

Accepted : 12 June 2021

Published: 22 June 2021

In today's world fuel demand is increasing day by day. Liquefied Petroleum Gas (LPG) is the most used fuel in Kitchen. This is filled in a cylinder in liquid state. These cylinders blast sometimes, the main reason of cylinder blast is gas leakage. So, to avoid this we need to detect the leakage of gas. For this we need an automatic gas leakage detection system which detects leakage of gas and gives alerts. This type of automatic security system can save people from dangerous blasts and prevent accidents. Nowadays IOT (Internet of Things) is widely used in day-to-day life. There are many home appliances which are based on IOT thus it becomes easier to manipulate them. As we know the kitchen is the most important part of our home, but we also heard about the disasters happening in the kitchen due to various reasons and many people lost their lives. There might be various reasons behind the cause of these disasters but the main and mostly happens is due to the leakage of LPG gas from the cylinder. As LPG gas is highly inflammable gas, a small leakage of gas can be costly for human life. So, if we can detect these leakages of gas before it causes any serious issue then we might save many lives.
\end{abstract}

Keywords : MQ2 gas sensor, LM35 temperature sensor, Arduino, Node MCU ESP8266, GSM module

\section{INTRODUCTION}

In India LPG (Liquefied Petroleum Gases) is most used for the cooking purpose. In this paper we proposed a system for detection of leakage of gas which is based on IOT. This system is helpful to detect the gas leakage so that the action can be taken before it causes any hazardous issue. The system consists of a MQ2 gas sensor which will detect the leakage of gas. As soon as it detects the gas an alert message is send to the user, the LED will be on, the warning message is to be displayed on the LCD screen and exhaust fan will be automatically switched on. We have additional sensors which will continuously monitor the oxygen level and the temperature of the room. 
In this paper, we present the design and implementation of IOT Based Smart Kitchen System. Gas leakage and cylinder blast is a big problem in today's world. If gas leakage is not detected fast it leads to explosion. So, we design and implement a system which prevents such types of accidents This system is wireless and includes GSM for communication purposes, Arduino UNO (which works as a microcontroller), also has a friendly user interface including LCD (LiquidCrystal Display).

This system also uses MQ-2 (gas sensor) and buzzer. This system responds rapidly to alarm incidents. Also, it is a low-cost system, and it consumes low power. Even in the absence of people at home it alerts people.

\section{Block diagram}

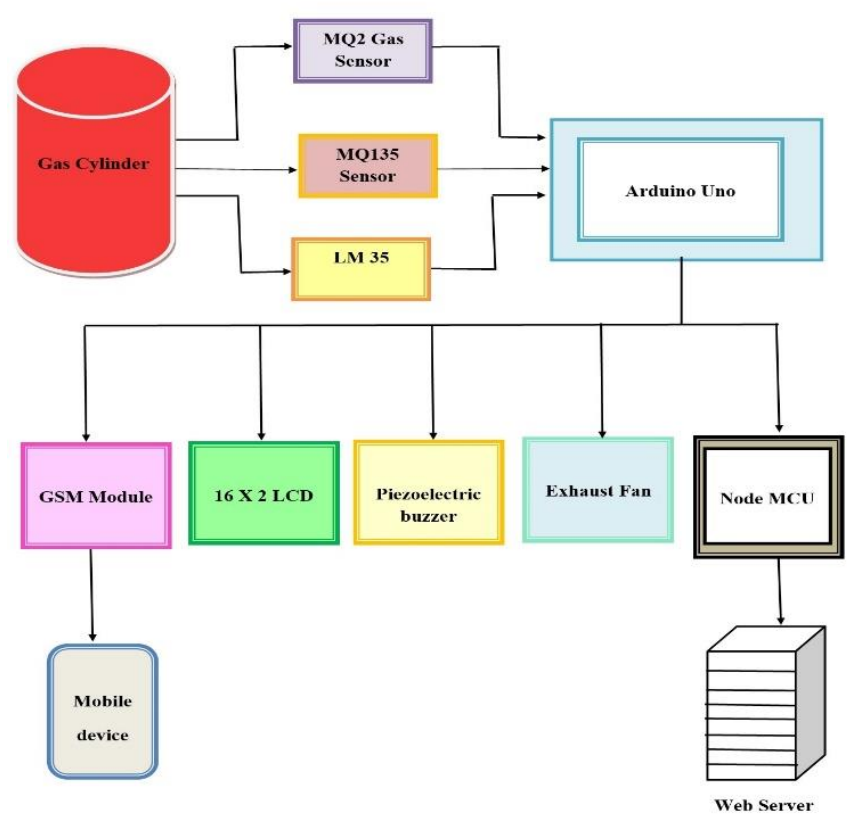

Fig 1. Block diagram

\section{METHODOLOGY}

Methodology is the systematic, theoretical analysis of the methods applied to a field of study. It comprises the theoretical analysis of the body of methods and principles associated with a branch of knowledge. Typically, it encompasses concepts such as paradigm, theoretical model, phases and quantitative or qualitative techniques. The methodological flow that we used in this project can be represented by following fig,

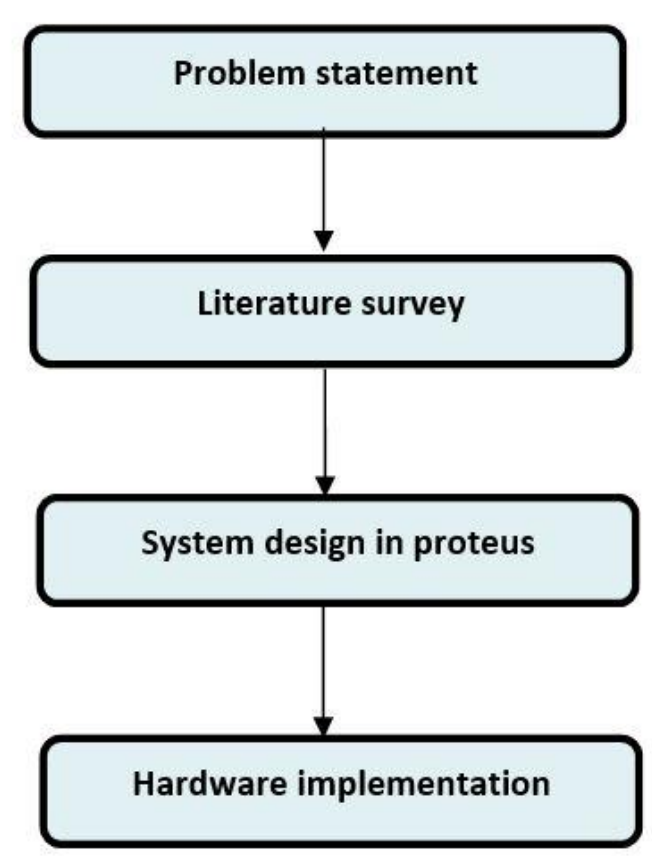

fig 2. Methodology Flow

\section{A Problem statement}

India's liquified petroleum gas (LPG) penetration reached 97.5 percent as on 1 April 2020. So, it is necessary to use it safely and without having any causality, with increase in use there is also increase in tragedies caused by gas leakage. We need an efficient, reliable, cost effective system that can be used in hotel kitchens as well as in home kitchens.

\section{B literature survey}

We done our literature survey through websites like google scholar and publishers like IEEE, ECCE, IOSRJECE, IJITEE. In these research papers system purposed for gas leakage detection with some additional features like fire alarm, gas monitoring, automatic cylinder booking etc. some systems 
purposed in these papers have more focus on safety and some have more focus on ease of use of LPG like automatic booking system. Also, some system uses IOT and WSN (Wireless Sensor Networks) to detect gas leakage at various location.

\section{System design in proteus}

Aim of this project is to detect gas leakage or sudden change in temperature in kitchen and alert the user by using SMS, LCD display, and buzzer. Also, we used IOT for constant monitoring of LPG and temperature levels. Before implementing the hardware for this system, we did simulation of this system in proteus. out of required components of this project we must add libraries for Arduino UNO, GSM module, MQ 2 gas sensor because proteus does not come with these libraries.

Then we did programming for Arduino UNO with the help of Arduino IDE which use c programming language. After successful compilation of program, we dumped the hex file of the program in the simulated version of Arduino UNO in proteus. we did connection as per our project in proteus and we successfully runed the simulation simulating both no gas leakage and gas leakage conditions.

\section{Hardware implementation}

After the simulation of system, we purchased all components that are required for our project that includes Arduino UNO, GSM GPRS SIM800C module, Node MCU ESP 8266, Mq2 gas sensor, LM 35 temperature sensor, Exhaust fan, 1-channel 5v relay module, LC display, piezoelectric buzzer, jumper wires, power supply cables etc. we did all the connections as per the simulation. We had to connect $10 \mathrm{~K}$ potentiometer to LCD to control its contrast.
We simulate the gas leakage environment by using lighter. As soon as we lighted the liter near MQ2 gas sensor the LC display changed to "Gas is leaking" message, the piezoelectric buzzer starts ringing, the warning SMS is sent to the concern person using GSM module. Also, we simulate the sudden change of temperature using lighter this time with the LM 35 sensor. The same process happed LCD display changed to "Temperature rising above danger level", piezoelectric buzzer starts to ring, the warning SMS is sent to concern person through GSM module. Also, the Exhaust fan starts to throw out smoke caused by fire out of the room. All these data of gas levels and temperature levels is sent to website using Node MCU ESP8266 module. Because of this user can remotely monitor the kitchen room so that immediate actions could be taken before the accident.

\section{Software design}

\section{A flow chart}

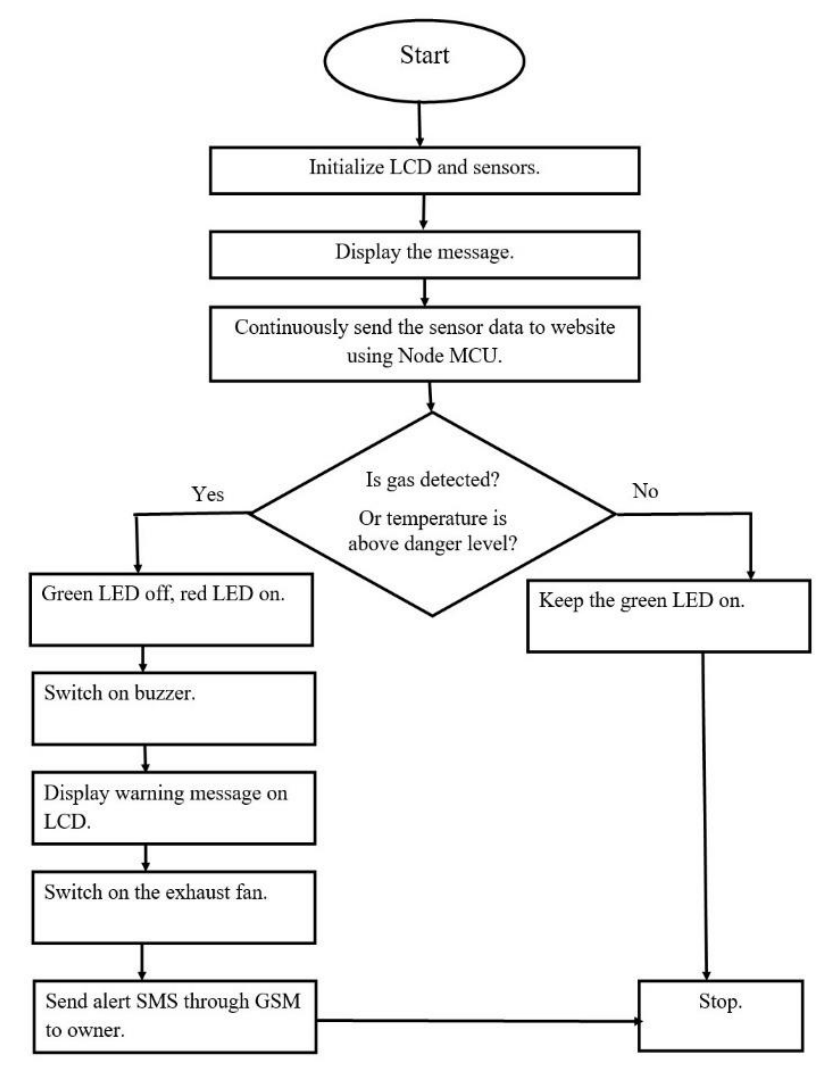

Fig 3. Flow chart 


\section{B Proteus Sketch}

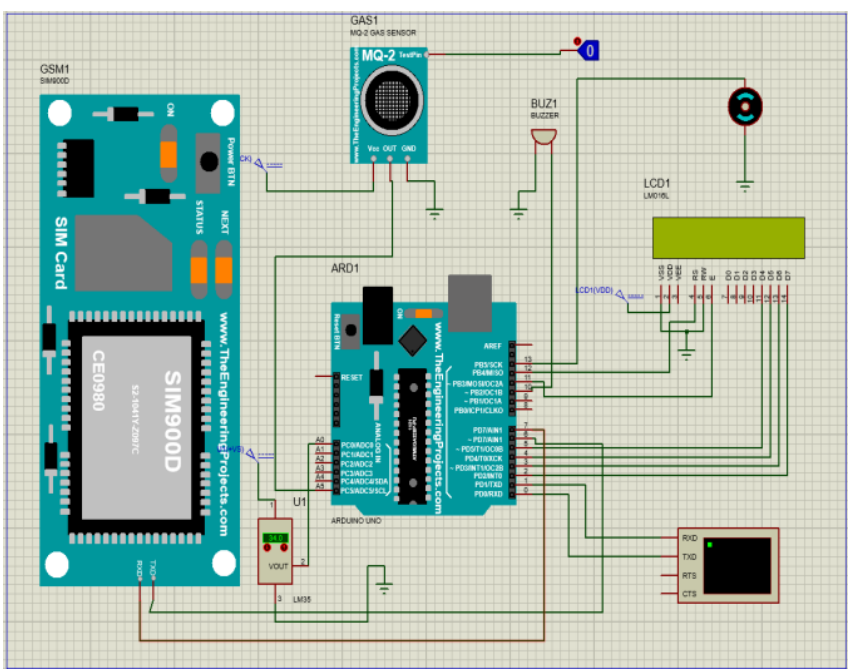

Fig 4. Proteus sketch

In proteus simulation we use Arduino UNO, GSM module, LCD, MQ2 gas sensor, Buzzer, LM 35, motor (to simulate fan). We used a logic toggle for simulating a gas leakage scenario. When the flag is " 0 " it indicates there is no gas leakage and when the flag is " 1 " there is gas leakage. We also used a virtual terminal for displaying the message sent by the GSM module. When there is no gas leakage means the toggle flag is "0" LC will display message "Gas Status is ok" as shown in below fig,

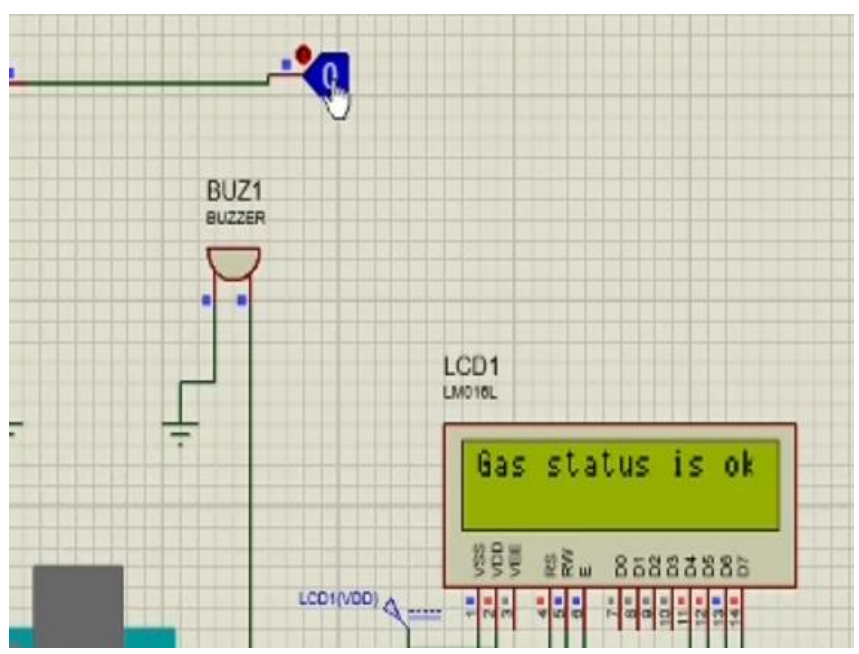

Fig 5. Proteus LCD Status.
As soon as we make the toggle flag "1" that is simulating the Gas leaking scenario the LCD message will change to "gas is leaking" as shown in below fig

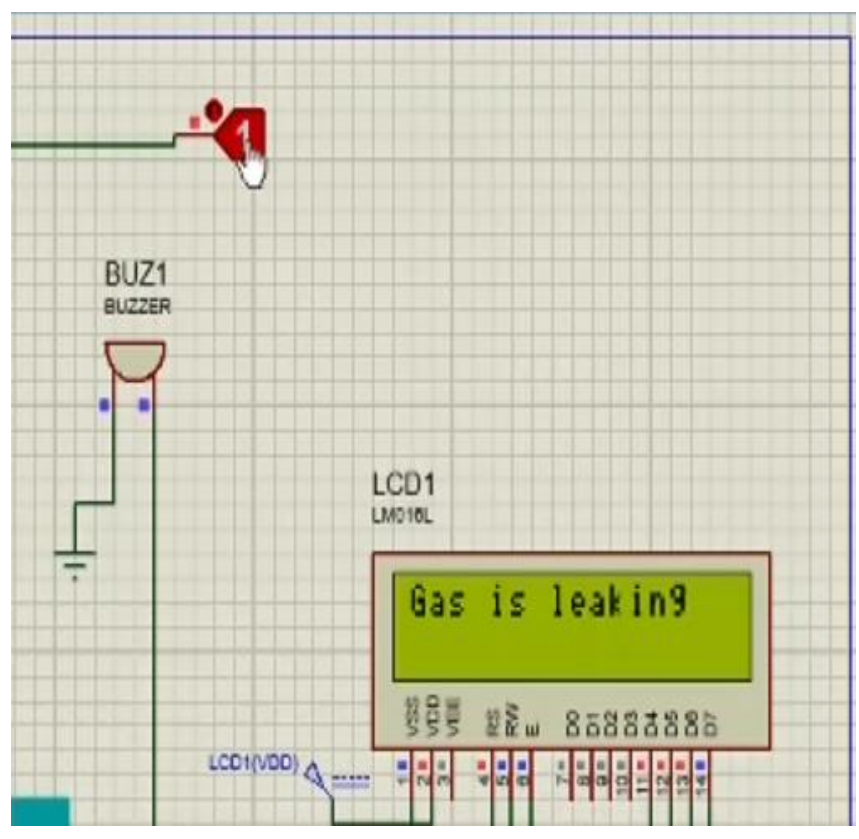

Fig 6. : Proteus LCD warning message.

Also, the GSM module will send a warning message to concerned person. This is simulated via virtual terminal as shown in below fig,

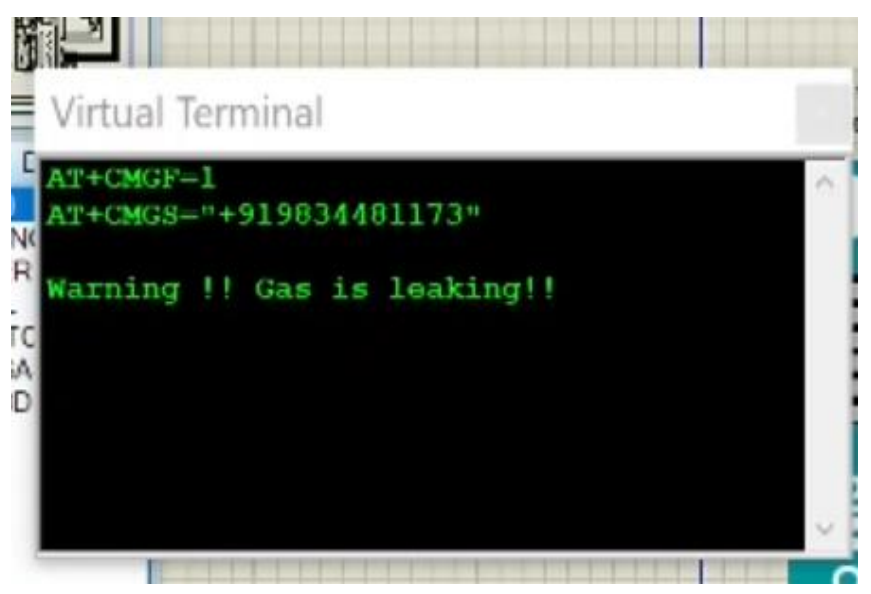

Fig 7. : Proteus virtual terminal.

Also, we are monitoring the temperature by using LM 35 by sending temperature readings to the lcd as shown in fig, 


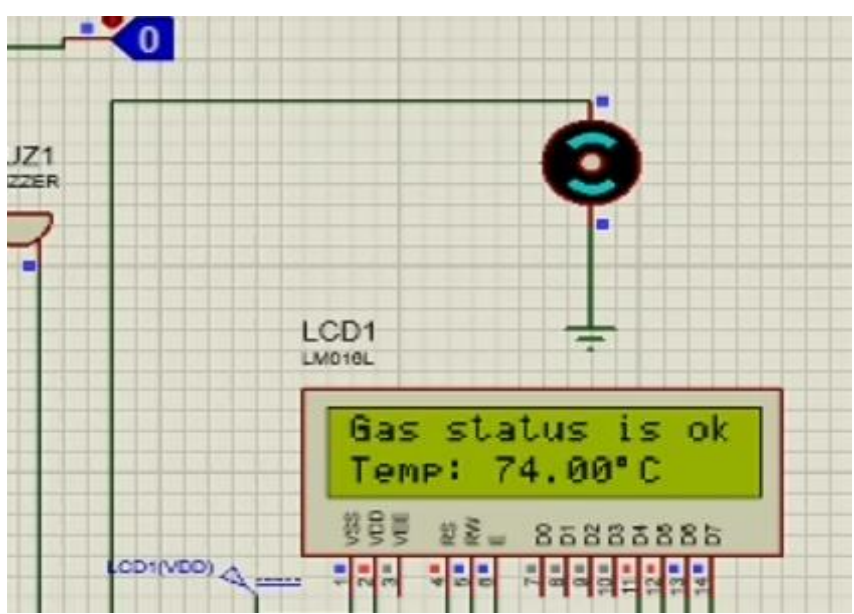

Fig 8. Temperature reading on LCD.

As soon as temperature exceeds the threshold value the warning message is send to the LCD as well as mobile device with help of GSM module as shown in below fig,

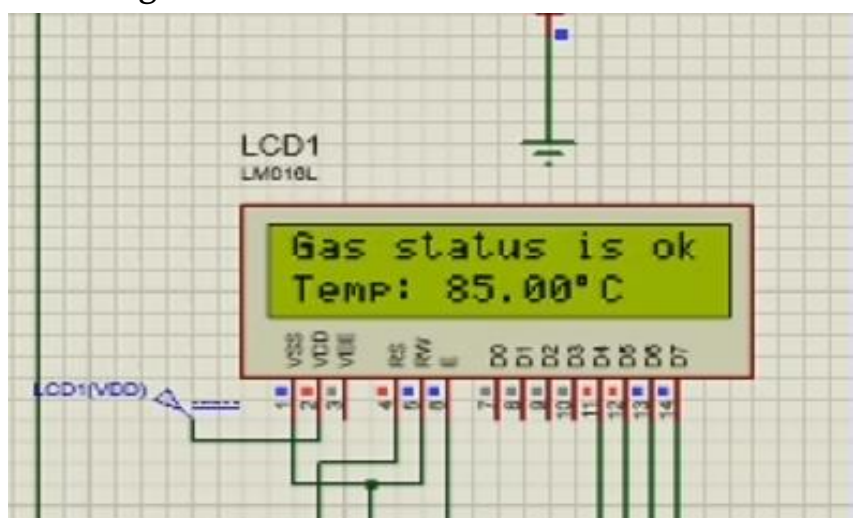

Fig 9. Temperature approaching threshold value

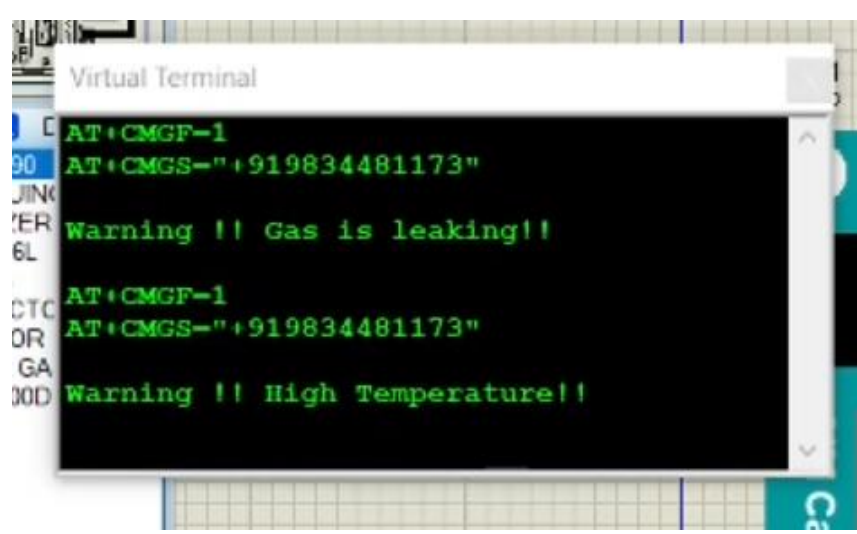

Fig 10. High temperature warning send via GSM

\section{Result}

In this IOT BASED SMART KITCHEN SYSTEM we used Mq2 gas sensor, LM 35 temperature sensor as input devices and LCD, GSM module, Exhaust fan as output devices. Also, we use IOT for Constant monitoring of gas level and temperature readings. The hardware setup is shown in fig below

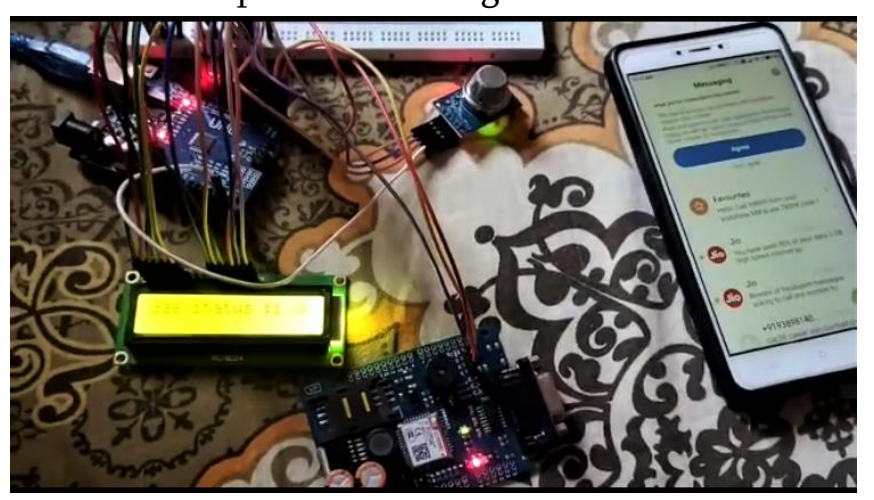

Fig 11. Hardware Setup

When there is no gas leakage or sudden change in temperature "gas status is ok" message will be displayed on LCD as shown in below fig,

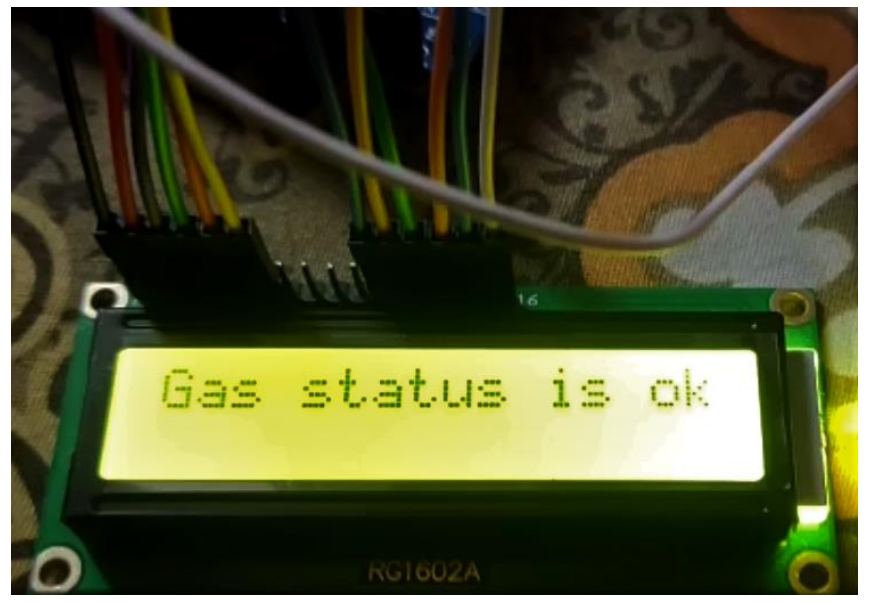

Fig 12. : LCD showing output of no gas leakage.

As soon as gas leakage is detected the piezoelectric buzzer will start ringing. Also, LCD will show warning message of gas leakage as shown in fig below, 


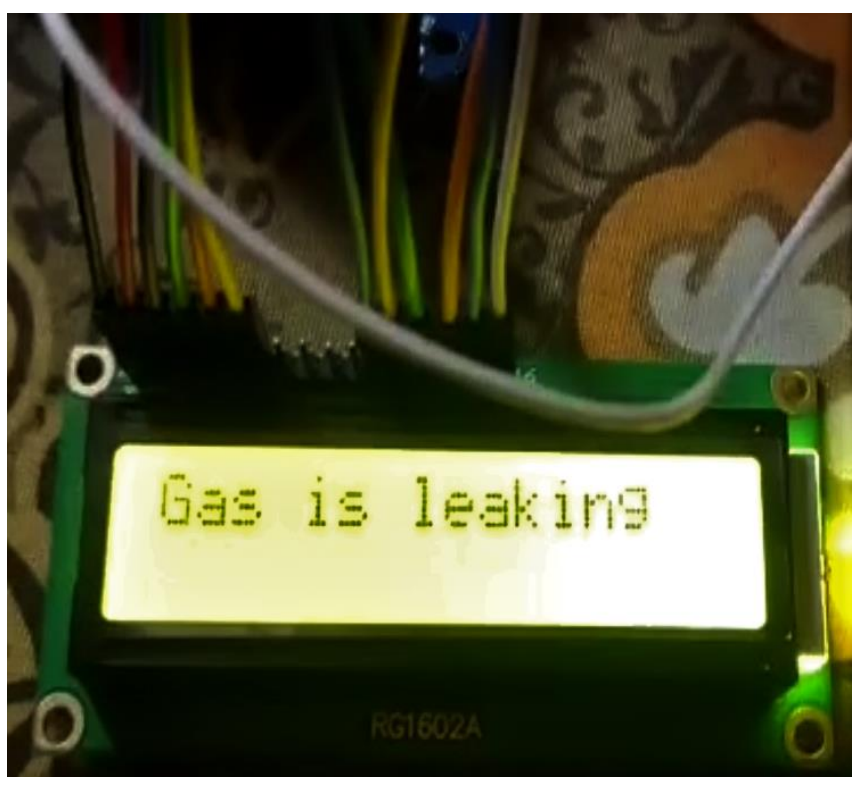

Fig 13. LCD showing the output of gas leakage.

Also, GSM module will send the warning message on the concern persons mobile as "' as shown in fig below,

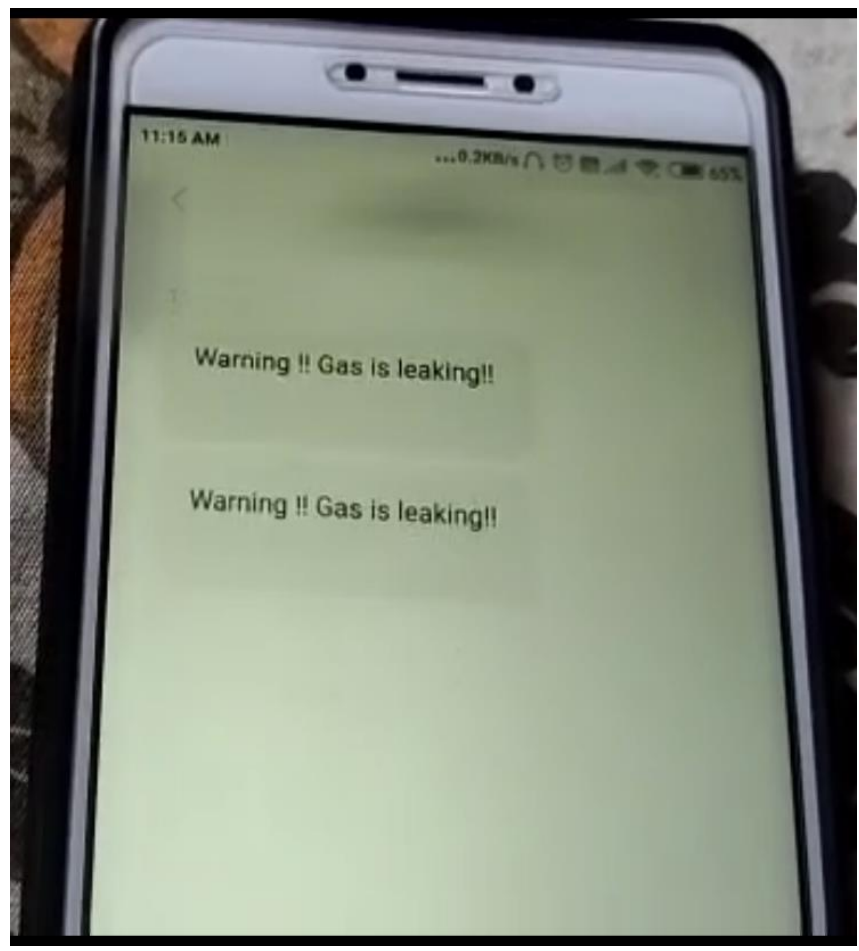

Fig 14. : Warning message send by GSM.

constant readings of gas send to the cloud using ESP 826601 module as shown in fig below,

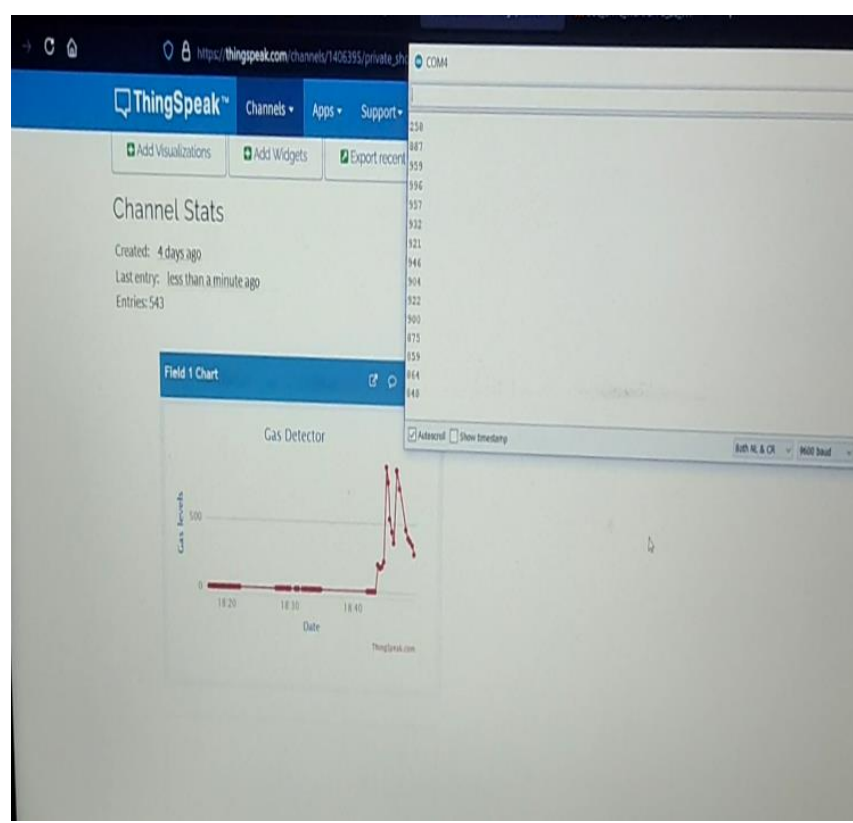

fig 15. data is sent to the website.

\section{Conclusion}

This project is very useful to prevent accident due to gas leakage. Each flame and gas detection application has its own unique safety hazards. If we implement this on Broadway, it is very successful. The main advantage of this simple gas leak detector is its simplicity and its ability to warn its stakeholders about the leakage of the Gas.

\section{REFERENCES}

[1]. "GSM Based Low-cost Gas Leakage, Explosion and Fire Alert System with Advanced Security" by Pritam Ghosh, Palash Kanti Dhar, International Conference on Electrical, Computer and Communication Engineering (ECCE), 9 February 2019.

[2]. L.P.G gas. Also due to continue monitoring by IOT it possible for the owner to remotely check the status of gas levels and temperature in the kitchen.

[3]. "Automatic Smart and Safety Monitoring System for Kitchen Using Internet of Things" by Harika Pudugosula, Proceedings of the 
International Conference on Intelligent Computing and Control Systems (ICICCS 2019) IEEE Xplore.

[4]. "IoT based system for detection of gas leakage and house fire in smart kitchen environments" by Marjan Ralevski, Biljana Risteska Stojkoska, 27th Telecommunications forum TELFOR 2019, Serbia, Belgrade, November 26-27, 2019.

[5]. "A Highly reliable Smart Kitchen Security Alarm System Based on Internet of Things" by Yun Wang, Tong Zhou, 2018 3rd International Conference on Materials Science, Machinery and Energy Engineering.

[6]. "SMART KITCHEN SYSTEM USING IOT" by Mrs Varsha R. Palandurkar, Simran J. Mascarenhas, Naaz D. Nadaf, Rupa A. Kunwar, International Journal of Engineering Applied Sciences and Technology, March 2020, Vol. 4, Issue 11.

[7]. "Gas Leakage Detection Based on IOT" by V Suma, Ramya R Shekar, Kumar A Akshay, 2019 3rd International conference on Electronics, Communication and Aerospace Technology (ICECA).

[8]. "A wireless home safety gas leakage detection system" by Luay Fraiwan, Khaldon Lweesy, Aya Bani- Salma, Nour Mani, 2011 1st Middle East Conference on

[9]. "LPG monitoring and leakage detection system" by Shruthi Unnikrishnan, Mohammed Razil, Joshua Benny, Shelvin Varghese, C. V. Hari, 2017 International Conference on Wireless Communications, Signal Processing and Networking (WiSPNET).

[10]. A review on micro-controller-based L.P.G gas leakage detector" by Vasudev Yadav, Akhilesh Shukla, Sofiya Bandra, Vipin Kumar, Ubais Ansari, SurajKhanna, journal of VLSI Design and Signal Processing, Volume 2, Issue-3.

[11]. "L.P.G gas leakage monitoring and alert system using Arduino" by Ayesha Siddika, Imam Hossain International Journal of Science and
Research (IJSR) ISSN: 2319-7064 Research Gate Impact Factor (2018).

[12]. "Early detection of leaks on gas cylinders using arduino based MQ-6 sensors" by E Fatkiyah, D Persada and D Andayati, Journal of Physics: Conference Series.

[13]. "Wireless sensor network on L.P.G. gas leak detection and automatic gas regulator system using Arduino" by L.Dewi and Y Somantri, International Symposium on Materials and Electrical Engineering (I.S.M.E.E) 2017.

[14]. "Hazardous gas detection using Arduino" by Prof. K.R.Katole, Vrushali Bagade, Bhagyashree Bangade, Ankita soni, Hiranmayee Kamde, IJSTE-International Journal of Science Technology \& Engineering, Volume 2, Issue 10, April 2016.

[15]. "Detection of liquefied petroleum gas using sensor through arduino uno microcontroller" by Aastha Singh, Mr. Manish Verma, Mr. Lumesh Sahu, International Research Journal of Engineering and Technology (IRJET) Volume: 05, Issue: 04, April - 2018.

\section{Cite this article as :}

Shubham More, Shridhar Shelar, Vaibhav Randhave, Prof. Ashwini Bagde, "IoT Based Smart Kitchen System", International Journal of Scientific Research in Science, Engineering and Technology (IJSRSET), Online ISSN : 2394-4099, Print ISSN : 2395-1990, Volume 8 Issue 3, pp. 479-485, May-June 2021. Available at

doi : https://doi.org/10.32628/IJSRSET2183198 Journal URL : https://ijsrset.com/IJSRSET2183198 